\title{
Climate change impacts and adaptations: lessons learned from the greater Zambeze River Valley and beyond
}

\author{
Channing Arndt ${ }^{1} \cdot$ Finn Tarp ${ }^{1,2}$
}

Received: 16 January 2015 / Accepted: 6 March 2015 / Published online: 17 April 2015

(C) UNU-WIDER 2015. This article is published with open access at Springerlink.com

\begin{abstract}
In this article, we assert that developing countries are much better prepared to undertake negotiations at the Conference of the Parties in Paris (CoP21) as compared to CoP15 in Copenhagen. An important element of this is the accumulation of knowledge with respect to the implications of climate change and the ongoing internalization thereof by key institutions in developing countries. The articles in this special issue set forth a set of technical contributions to this improved understanding. We also summarize five major lessons related to uncertainty, extreme events, timing of impacts, the inseparability of the development and climate agendas, and the rate of assimilation of climate and development information in key institutions. They are drawn from the Development Under Climate Change (DUCC) project carried out by UNU-WIDER of which the countries of the Greater Zambeze Valley formed a part. Finally, we outline three areas for future research.
\end{abstract}

\section{Introduction}

In December 2009, the 15th meeting of the Conference of the Parties (CoP) to the United Nations Framework Convention on Climate Change took place in Copenhagen Denmark. During the run up to CoP15, both of the authors of this introductory article were professors in the Department of Economics at the University of Copenhagen with long established interests in development issues and emerging interests in climate change, especially the implications of climate change for development trajectories and strategies. CoP15 promised to pay particular attention to development issues, not least the complications added by climate change to the already arduous

This article is part of a Special Issue on "Climate Change and the Zambezi River Valley" edited by Finn Tarp, James Juana, and Philip Ward.

Finn Tarp

Finn@wider.unu.edu

1 World Institute for Development Economics Research, United Nations University, Katajanokanlaituri 6 B, 00160 Helsinki, Finland

2 Department of Economics, University of Copenhagen, Copenhagen, Denmark 
development challenges facing these countries in general and low income countries in particular. As such, the impending CoP15 negotiations were impossible for us to ignore.

Over the course of 2009, our assessment of the likelihood of success of CoP15 became increasingly pessimistic. This pessimism was certainly not uniquely harbored in ourselves. For example, a November 82009 article in Time magazine questioned in the headline: "Is there any hope for agreement at Copenhagen?" However, our particular concerns were rooted in our cumulative observations as development professionals considering the implications of climate change in progressively greater detail. Simply put, not enough was known about climate change and its implications for development trajectories and strategies to permit effective negotiation. This was, in our view, true across the full slate of negotiating parties. To be sure, developed country negotiators were well versed in the latest climate science and, at a minimum, had access to the latest thinking on the implications of climate for developing countries. However, this latter information base was, at the time, at best poorly developed and highly fragmentary. Even in major international institutions concerned with development issues, the process of assimilating the existing information was in initial stages.

More importantly, the existing (inadequate) information base had barely begun to penetrate key decision-making units within developing countries. In particular, rigorous analysis of the implications of climate change for overall growth and development prospects was essentially not present, much less comprehensively debated and internalized, in any country of which we were aware. This was, in our view, deeply problematic. One wondered how developing countries could effectively negotiate before key decision-making institutions within those countries had really even begun to come to grips with the issues.

In contrast to $\mathrm{CoP} 15$, we view the upcoming $\mathrm{CoP} 21$ negotiations with guarded optimism. Once again, there are many sources for this more positive outlook including the offer style negotiation format and the recent announcement of commitments from China and the United States. We also believe that considerable progress in understanding the implications of climate change for development trajectories and for development strategies ranks as a major contributor. This is to the credit of tens of thousands of people working in thousands of institutions within nearly all of the countries on the globe. As emphasized above, the information needs not only to be present; it must also be debated and internalized.

The subsequent articles in this special issue set forth a set of technical contributions to this improved understanding. These contributions stem from the Development Under Climate Change (DUCC) project undertaken by the World Institute for Development Economics Research of the United Nations University (UNU-WIDER). The DUCC program was a direct result of the observations described above. Under DUCC, detailed country level analysis, focused on growth and development prospects, in countries containing the Zambeze River Valley (ZRV) as well as in Ethiopia, Ghana, South Africa, Tanzania and Vietnam.

Here, in this introductory article, we focus on some of the major lessons that have been learned since CoP15, including thoughts on how these lessons are being incorporated into ongoing development policy thinking at the country level. While the articles in this issue focus on the countries of the ZRV, we draw here not only upon this experience but also on experience accumulated in work in the other countries mentioned just above as well as the extant literature. As such, this introductory article departs from the practice of principally summarizing/synthesizing the articles in the special issue. The final article in this special issue undertakes this task alongside the presentation of new information.

The remainder of this introductory article is structured as follows. Section 2 considers five major lessons. These relate to uncertainty, extreme events, timing of impacts, the inseparability of the 
development and climate agendas, and the rate of assimilation of climate and development information in key institutions. The final section, 3, proposes three priority areas for future research.

\section{Lessons learned}

\subsection{Uncertainty}

In the run up to CoP15 in Copenhagen, it was relatively common to encounter high level officials within governments, particularly in developing countries, who would express serious concern that the wetter (dryer) future forecasted by one climate modeling group would be directly contradicted by a dryer (wetter) forecast from a subsequent climate modeling group. As shown by Schlosser and Strzepek in this volume (amongst others), the sign of precipitation changes at relatively small scales (such as a country) can typically not be projected with a high degree of confidence. Hence, while forecasts of temperature increase over time are very robust outputs from climate models, planners and policymakers, including private sector actors, must confront a frequently broad range of precipitation uncertainty across projected climate futures.

This uncertainty in terms of precipitation is an unsettling reality worldwide and particularly in developing countries, where large shares of the population rely upon agriculture for livelihoods. The internalization of this uncertainty by developing country decision-makers is obviously a good thing. It goes a long way to avoiding the possibility that a country, or agents within a country, will spend considerable resources preparing for a dryer (wetter) future when a wetter (dryer) future may in fact be in the offing. Communication of uncertainty at a basic level can be achieved by analyzing a limited number of climate projections with certain properties. For example, World Bank (2010) [published after CoP15] presents detailed analyses for a series of countries based on four general circulation models. These four projections were taken on the basis of their global properties for temperature and precipitation change.

This is clearly a step in the right direction in comparison with the analysis of only one potential climate future, which is unlikely to be correct. Even on the basis of a handful of projections, the logic behind robust or even 'no regret' climate policy responses, as discussed by Hallegatte (2009) among others, can be fairly easily discerned. At the same time, reliance on a set of arbitrarily selected climate scenarios, with each one described as 'equally unlikely', also has obvious limitations. In particular, the selection of climate scenarios is unlikely to delineate the support of the potential impact distribution. It also provides no sense of where, within the support of the distribution, probabilities are likely to concentrate.

The articles in this special issue are particularly concerned with the conversion of uncertainty into risk, where both terms are employed with the meanings defined by Knight (1921). Used in this sense, uncertainty refers to a situation where the probability of a particular outcome, and perhaps even the support of the distribution of outcomes, is not known. Risk, on the other hand, is characterized as a situation whereby the distribution of potential outcomes is known and the actual outcome is not. Hence, the upcoming turn of a fair and known roulette wheel is risky, but not uncertain.

A common concern voiced with respect to the estimation and presentation of distributions of climate, biophysical, and economic outcomes is that decision-makers, particularly politicians, will be incapable of understanding them. It is, of course, quite possible to find politicians with either an inability or unwillingness to grapple with ranges of potential outcomes. However, in our experience, decision-makers are frequently very comfortable with ranges of outcomes, 
particularly when the sources of variation are explained honestly and succinctly. And, this comfort level tends to rise as one ascends the decision-making hierarchy (though this is certainly not an iron rule). The reason, in our view, is that politicians and others confront decision-making under uncertainty every day. Hence, the challenge is one of communication rather than concept.

While communication of distributions of outcomes once they have been estimated is not that difficult, the actual technical task of converting climate, biophysical, and economic outcomes from uncertainty to risk is challenging. This is amply illustrated in the five articles that follow in this special issue. At the same time, the process of doing so brings other advantages. In particular, the conversion of uncertainty to risk implies specifying the support of the distribution of potential outcomes. A purposeful attempt to define the support of the distribution of outcomes is qualitatively different from multiple efforts to estimate mean, mode, or median outcomes (i.e., those within the center of the distribution). Efforts to specifically target the tails of the distribution of outcomes would logically be more likely to unearth low probability and high impact possibilities. It is to these possibilities that we now turn.

\subsection{Extreme events}

As discussed by Weitzman (2011), the characterization of the distribution of potential climate outcomes as 'fat-tailed' has potentially profound implications for decision-making with respect to climate change. There may be strong rationales for taking action today to avoid low probability, high impact events in the future, in much the same way that homeowners typically purchase insurance to counter the possibility of extreme events such as fire. Characterization of the tails of distributions is difficult empirically because, by definition, the number of observations that one has to work with is relatively small. Hence, consideration of the tails of distributions is bound to remain an active area of research, as will be discussed in section 3 .

Nevertheless, even on the relatively short time scales considered in this special issue, consideration of extreme outcomes, such as droughts, floods, and cyclone strike, is of strong interest. In the articles that follow as well as in country cases considered elsewhere (e.g., Arndt et al. 2014; 2015; CIEM 2012), magnification, due to climate change, of the probability and/or the severity of extreme events frequently generates a longish negative tail in the distribution of socio-economic outcomes (items such as GDP, agricultural production, and hydropower output). For developing countries concerned with prospects for economic growth, events that interfere with long run accumulation processes are particularly pernicious as small changes in growth rates eventually accumulate to big changes in outcomes.

For example, as discussed in this special issue, magnification of the intensity/severity of flooding events in Mozambique, a widespread coastal country traversed by numerous rivers, could repeatedly destroy road stocks and other infrastructure with negative implications for growth. For Malawi, a similar flooding effect is generated though to a lesser degree because Malawi is a highland that is not downstream and because of greater population densities resulting in a denser road network characterized by a lower degree of criticality. ${ }^{1}$ In Vietnam, the combination of densely populated and very low lying river deltas, sea level rise, and cyclone strike substantially magnifies the probability of highly damaging storm surges (CIEM 2012). These possibilities should enter the calculus of decision-making today.

\footnotetext{
${ }^{1}$ In contrast, in Mozambique, there is currently only one road linking the Northern, Central, and Southern regions of the country.
} 
In South Africa, a series of factors including (i) elevation of much of the country, (ii) lower flood risk, (iii) robust road networks, (iv) a relatively small share of capital exposed to storm surge, and (v) an intricate water supply system that permits transfer of water across river basins, generally leads to fairly muted impacts of climate change on overall economic growth. This includes a relatively small 'bad tail' associated with the distribution of these growth outcomes. Rather than at the aggregate level, extreme negative outcomes in South Africa occur in regions or sectors that may be especially vulnerable to particular sets of climate outcomes (Arndt et al. 2015). Once again, these extremes and their implications are among the more policy relevant findings of the analyses conducted thus far.

\subsection{Timing}

For the purposes of decision-making, the timing of impacts is of obvious relevance. Across all of the countries considered under DUCC, we find limited impacts on growth as a consequence of climate change in the relatively near term - over the next decade and a half and perhaps beyond. The combination of long time scales (at least in human terms) and high levels of uncertainty with respect to many climate outcomes leads naturally to the concept of development as adaptation. As has been emphasized elsewhere (e.g., World Bank 2010), the flexibilities afforded by human capital and functional institutions may be the best possible current adaptation strategy. These elements are also cornerstones of contemporary development strategy. Hence, in many ways, the prospect of climate change adaptation frequently serves to reinforce the development imperative.

This is, however, not true in all ways. An excellent example comes from outside of ZRV, in Vietnam. As noted above, the combination of densely populated and low lying river deltas, sea level rise, and cyclone strike present a clear and increasing threat. This is true even if the historical frequency and severity of cyclone strike remains unchanged. This is so because the platform afforded by sea level rise dramatically increases the area at risk of inundation from storm surge (Neumann et al. 2012). With continued sea level rise, Vietnam will eventually face serious choices with respect to their river deltas, not least the Mekong. However, policies introduced today can help to channel future economic growth towards less vulnerable zones. If done deliberately and carefully, these kinds of adaptation policies could significantly reduce the share of economic activity at risk in the latter half of the 21 st century at little to no growth cost (CIEM 2012).

Another example prevails almost everywhere. Road pavement mixes are chosen to withstand certain maximum temperature thresholds. As the frequency and severity of extreme heat events are robustly expected to increase, changes to these mixes are in order. Because the design life of paved roads are frequently 20 years or more, it makes sense to consider future temperature rises in road design today. Changes in design standards to cope with changes in precipitation and/or the frequency/severity of flooding events are somewhat less straightforward due to the uncertainties inherent in changes in precipitation. Nevertheless, they are another example of a consideration that very rationally should enter into development calculus as a consequence of forecasted climate change.

\subsection{Inseparability of the development and climate agendas}

One important upshot of the discussion from the preceding three subsections is the inseparability of the development and climate agendas. In the subsection on timing presented above, we covered three illustrations of adaptation. The first simply poses development as an excellent form of adaptation. The second refers to the geographic pattern of economic growth as it pertains to Vietnam and the risk of storm surge. And, the third considers design standards 
for roads. Of these, none fall within the purview of ministries of environment (where a great deal of effort with respect to climate change adaptation is often nonetheless concentrated). Only one, road design, falls principally within the purview of a technical ministry. The remaining two illustrations fall principally within the purview of the central strategic resource allocating bodies within government, typically ministries of economics and finance.

The importance of the central allocating organs only increases when one adds the mitigation challenge on top of the adaptation challenges. In short, major investment and policy decisions being made today will be major determinants of the robustness/vulnerability of the society in mid-century and beyond, when the impacts are widely expected to become more severe. Importantly, the collective sum of decisions on emissions will eventually determine the severity of impact.

The central allocating bodies of governments are, as a result, absolutely critical; and it is here that, in our view, significant progress has been made. As noted, in 2009, very few central allocating organs in developing countries contained people with more than a cursory understanding of climate change issues and their implications for decision-making. This has changed. We know our own experience best and can report substantial engagement with central ministries in a wide array of countries. In addition, rather than just provide reports and results, we have increasingly been able to provide systems, tools, and training such that local analysts, often incorporating locally developed models, undertake the majority of the analysis. ${ }^{2}$ The process has been two-way in that governments have reached out and the research community has responded. The result is that many developing country governments are in a far better position to actually negotiate.

\subsection{The state of assimilation of climate information broadly defined}

Overall, the situation is improved yet not necessarily good - hence the guarded optimism. For example, with respect to the notion of inseparability in focus in the preceding subsection, substantial momentum still exists to treat climate change as a distinct and separable problem. Climate finance is perhaps the best illustration of this momentum. Even as the need for 'mainstreaming' climate adaptation and mitigation is increasingly recognized, climate finance is becoming increasingly fractured with a large number of funds and vehicles coming into existence, often with particular objectives. ${ }^{3}$ More broadly, decisions from recent CoP meetings continue to emphasize a distinction between climate finance as new and additional to other forms of finance even though this distinction cuts directly against mainstreaming (Ayers and Huq 2009) and despite very substantial conceptual and practical problems to maintaining the distinction at all (Arndt 2015).

More generally, given the complexity of the issues and the breadth of their implications, the process of assimilating climate issues into mainstream decision-making is bound to take a long time. The experience of international organizations is illustrative in this regard. One of the authors was involved in the World Bank's Economics of Adaptation to Climate Change study and the Green Growth report, part of the African Development Report series, for the African Development Bank. Flagship documents such as these always pose challenges; nevertheless, these reports posed particular difficulties due, in significant measure, to the relative lack of a conventional wisdom upon which to build.

\footnotetext{
${ }^{2}$ See http://www1.wider.unu.edu/climateresearch/ and http://www1.wider.unu.edu/ducc/

${ }^{3}$ See www.climatefundsupdate.org for summary information on existing funds. Also see UNU-WIDER (2014).
} 
The same holds true for developing country governments. There remains a tremendous amount to do almost everywhere. Returning to CoP21, it is (we hope) not the case that every country needs to achieve a sophisticated assimilation threshold before the negotiations can succeed. Under the offer system currently envisioned for the negotiations, leading countries can have significant influence. So, the very substantial progress realized over the past 6 years in, for example, South Africa has the potential to generate overall positive momentum.

\section{Future research}

To finish, we identify three areas of future research. The first of these mainly highlights a set of particularly pertinent issues related to the analysis of impacts and adaptation drawn from the articles in this special issue. The remaining two are more forward looking and focus on (i) world prices for fossil fuels and (ii) the relative competitiveness of developing countries, particularly those in Africa, under a serious global mitigation regime.

With respect to impacts and adaptation, continued focus on extreme events represents an obvious priority. From historical experience in the ZRV, it is clear that flood events can be devastating. At the same time, flood modeling is challenging due to time and location specificities while signals from climate models tend to be coarse both spatially and temporally. There is a need for revisiting these issues particularly in light of the relatively large impacts generated. In addition, recent research by Lobell et al. (2013) identifies heat threshold effects for maize production in the United States. It is important to learn more about the nature of these threshold effects for crops grown in developing countries. The existence of similar threshold effects across multiple crops in developing areas could imply a more rapid onset of serious negative implications for crop production. Other important future research areas are listed within the individual articles of this special issue.

Second, with respect to prices for fossil fuels, the work of Paltsev (2012) deserves to be followed up. As shown by Paltsev, serious global mitigation tends strongly to drive down fossil fuel prices (with the exception of natural gas which experiences a temporary rise before declining). This is logical and highly relevant to low income countries, particular in Africa, where the energy intensity of GDP tends to be relatively high. The relative price movements highlighted by Paltsev point to a choice between less and less use of increasingly cheap fossil fuels or more and more use of increasingly expensive fossil fuels. While projecting the future level of prices of fossil fuels is intrinsically difficult, it should be possible to build upon the work by Paltsev to consider the implications of mitigation for fossil fuel prices in greater detail. This work would usefully be married to country level work on the implications of these price changes for living standards in developing countries.

Finally, more work is required on the relative competitiveness of developing regions under mitigation regimes. As shown by Lanz and Rausch (2011), typical parameterizations of the power sector in workhorse models of global trade do a poor job of emulating actual technical choices including for renewables. To the knowledge of the authors, there has yet to be a rigorous consideration of the relative benefits of Africa's substantial endowments of sun, wind, and hydropower resources in a world characterized by an effective mitigation regime. They could turn out to be large and therefore deserve close scrutiny to the benefit of a continent where the effects of climate change are otherwise unfavorable, as illustrated in what follows. 
Open Access This article is distributed under the terms of the Creative Commons Attribution 4.0 International License (http://creativecommons.org/licenses/by/4.0/), which permits unrestricted use, distribution, and reproduction in any medium, provided you give appropriate credit to the original author(s) and the source, provide a link to the Creative Commons license, and indicate if changes were made.

\section{References}

Arndt C Development assistance and climate finance. UNU-WIDER working paper 2015/XX, Helsinki

Arndt C, Schlosser CA, Strzepek K, Thurlow J (2014) Climate change and economic growth prospects for Malawi: an uncertainty approach. J Afr Econ 23(4):ii83-ii107. doi:10.1093/jae/eju013

Arndt C, Cullis J, Gabriel S, Hartley F, de Jager G, Makrelov K, Schlosser CA, Strzepek K, Alton T, Cartwright A, Chang A, Gebretsadik Y, Robertson G, Thurlow J (2015) An uncertainty approach to modelling climate change risk in South Africa. UNU-WIDER working paper 2015/XX, Helsinki

Ayers JM, Huq S (2009) Supporting adaptation to climate change: what role for official development assistance? Dev Policy Rev 27(6):675-692

CIEM [Central Institute for Economic Management] (2012) Implications of climate change for economic growth and development in Vietnam to 2050. http://www.wider.unu.edu/publications/miscellaneous/en_GB/report2012-ducc/

Hallegatte S (2009) Strategies to adapt to an uncertain climate change. Glob Environ Chang 19(2):240-247

Knight FH (1921) Risk, uncertainty and profit. Hart, Schaffner \& Marx; Houghton Mifflin Co, Boston

Lanz B, Rausch S (2011) General equilibrium, electricity generation technologies and the cost of carbon abatement: a structural sensitivity analysis. Energy Econ 33:1035-1047

Lobell DB, Hammer GL, McLean G, Messina C, Roberts MJ, Schlenker W (2013) The critical role of extreme heat for maize production in the United States. Nat Clim Chang 3:497-501

Neumann JE, Emanuel KA, Ravela S, Ludwig LC (2012) Risks of coastal storm surge and the effect of sea level rise in the red river delta, Vietnam. Working paper 2012/081, World Institute for Development Economics Research, Helsinki

Paltsev S (2012) Implication of alternative mitigation policies on world prices for fossil fuels and agricultural products. Working paper 2012/065, World Institute for Development Economics Research, Helsinki

UNU-WIDER (2014) Aid, environment and climate change. ReCom Position Paper, Helsinki

Weitzman ML (2011) Fat-tailed uncertainty in the economics of catastrophic climate change. Rev Environ Econ Policy 5(2):275-292

World Bank (2010) Economics of adaptation to climate change: synthesis report. World Bank, Washington 